\title{
Developing the assistive technology consumer market for people aged $50-70$
}

\author{
GILLIAN WARD*, SIMON FIELDEN†, HELEN MUIR + , \\ NIKKI HOLLIDAY* and GERRY URWIN§
}

\begin{abstract}
Within the United Kingdom (UK), assisted living technologies are mostly provided through statutory health and social care services following assessment of individual need and application of eligibility criteria. This paper describes the first UK study to explore and develop business approaches and innovations required to make electronic assisted living technologies more accessible to consumers in their fifties and sixties. A robust mixed-method approach was used including a large sample size for a consumer survey, triangulation of methods and confirmation of research findings through validation workshops. This three-year study makes significant and original contributions to understanding consumer needs in this rapidly changing market and offers unique insights into the needs and wants of people aged $5^{\mathrm{O}-70}$. Analysis shows significant differences between consumer and business perceptions, indicating that marketing is not closely aligned to consumers' needs and is affecting the development of the market. New approaches to consumer-led business models are presented to improve information and marketing aimed at $5^{\mathrm{O}-7 \mathrm{O}^{-} \text {-year-old con- }}$ sumers. A 'Broker/Independent Advisor' business model showed most potential for meeting the needs of both consumer and business stakeholders. Findings support future development of an assisted living consumer market to meet growing levels of need and demand, and to offer greater consumer choice of mainstream technologies to enable people to age in place.
\end{abstract}

KEY WORDS-assistive technology, business model, older consumer market, cocreation.

\section{Introduction}

Recent consecutive United Kingdom (UK) governments have supported the preference for people with health and social care needs to retain independence and remain in their own homes for as long as possible. Ageing in place

* Centre for Technology Enabled Health Research, Coventry University, UK.

$\uparrow$ Birmingham Community Healthcare NHS Trust, UK.

* Research Office, Coventry University, UK.

$\S$ Faculty of Business and Law, Coventry University, UK. 
describes a person living in the residence of their choice, for as long as they are able to as they age, and includes access to services (or other support) they might require as their needs change over time. The necessity to embrace selfmanagement and the wider wellbeing and active ageing agenda (Walker 2009) reinforces this. Electronic assisted living technologies (eALT), including telehealth and telecare, offer new opportunities for digitally enabled products and services to support people with their health, wellbeing and social care needs as they age in place (Ward and Ray 2014).

In the UK, provision of eALT products and services is predominantly through the National Health Service (NHS) and local authority social services. However, reductions in public funding, the need for personal financial assessments, means testing and strict application of eligibility criteria for statutory services means that many people are not eligible for such services. As a result, people are beginning to look to the self-funded consumer market to meet their needs, and governments are eager to implement digital solutions (Westbrook 2015). However, the consumer market in this area is not well developed in the UK. Direct consumer sales are low, with many companies selling to public service providers rather than directly to end users. This paper describes the first UK study that aimed to explore and develop business approaches and innovations required to make eALT more accessible to consumers in their fifties and sixties.

\section{Background}

Within England and Wales, public-sector service provision (including eALT provision) is being restricted due to diminishing budgets and stringent application of the Fair Access to Care Services (FACS) criteria (Social Care Institute for Excellence 2013). Scottish councils are also tightening eligibility criteria and increasing service charges (Audit Scotland 2012). Together with the growing number of people living longer (Office for National Statistics 2011) and the increase in those living with long-term conditions (Department of Health 2012), the consumer market must expand to meet growing levels of need and demand which otherwise may overwhelm public services.

The Care Act states that if none of the person's needs meet the eligibility criteria, local authorities in England must give advice and information about what can be done to prevent or delay the development of further needs in future (Care Act 2014: 23:13). Greater signposting to other resources, including the consumer market, must become part of routine practice for health and social care practitioners. These practitioners often look for practice guidance such as that provided by the National Institute for Clinical Excellence, but such practice guidelines do not exist for a consumer 
market. Organisations such as the Research Institute for Consumer Affairs (RICA formerly Ricability) provides information on home technology to older and disabled consumers but not directly to health and social care practitioners. At the same time, there is a growing consumer interest in managing health and wellbeing, evidenced by an increased availability of health devices (e.g. to monitor blood pressure, walking activity, heart rate) on the high street. However, generally, consumer awareness of eALT is low (Carers UK 2013: 6-7).

People now aged 50-70 years old, the 'baby boomers', were the first generation to enjoy mass-manufactured goods and are reported to be more demanding consumers (Higgs et al. 2009; Jang and Ham 2009; Ross 2008) with an individualistic and youthful outlook (Packaged Facts 20o6, cited in Yoon, Cole and Lee 2009). They have experienced technology in their lives and may expect technology to be part of their older age or consider its use to support older adults they may be caring for (Coughlin 1999). The Wealth and Assets Survey of Great Britain reported that those aged $55^{-64}$ years old have the greatest mean and median household wealth of all age groups, with older people (over $6_{5}$ years old) maintaining higher wealth than younger age groups (Office for National Statistics 2009). Despite a welcome reduction in the number of people in later life living in poverty, it remains an issue for a significant minority of older people (Age UK 2011 ) and therefore the consumer market will not be accessible for all older people and statutory provision will need to continue to meet their needs. However, the consumer market offers greater choice of design and range of products to meet people's lifestyle choices if they can afford it and some older consumers have money which they are willing to spend and may be amenable to purchasing eALT (Reisenwitz and Iyer 2007).

There is a lack of research on the older consumer despite the fact that older people represent a significant proportion of the consumer market (Age UK 2010; Yoon, Cole and Lee 2009). 'Baby boomers' are an important market segment and are likely to consider the private purchase of eALT to support themselves and their loved ones (Carers UK 2013). This segment of the market is largely untapped and presents opportunities for manufacturers, suppliers and retailers in the eALT industry. However, the current industry is not 'retail ready'; with most businesses being small to mediumsized enterprises (SMEs), of which few sell directly to consumers. Their 'customers' are mainly health and social care services with sales made through business-to-business contracts.

There is also a lack of high-quality research evidence informing the use of eALTs to support independent living in older age. The Audit Commission conducted a review of eALT and proposed that there was a 'tantalising possibility' for assistive technology to provide independence, functional 
benefits and cost savings (Audit Commission 2004: 443). Blashcke, Freddolino and Mullen (2009: 651) concluded that we are 'far from knowing what types of [assistive technology and information and communications technologies] work well, with what types of users, under what conditions and for how long' and that the aggregated lessons learned that can be generalised across age, gender and nationality are few.

There is, however, a growing body of literature building from case studies and non-blind smaller randomised controlled trials which are suggesting that eALT has a role in improving function and independence where it is tailored to individual need (Woodcock et al. 2013). In reality, cost-effectiveness of eALT has been difficult to prove, with only half of eALT (telehealth) economic evaluations concluding that there are savings to be made from astute use of eALT, with 7 per cent of studies concluding that eALT costs money and 43 per cent of studies providing no conclusion either way (Stroetmann et al. 2010). In addition, there is little evidence regarding people's experiences of purchasing eALT privately, and what there is tends to be anecdotal reports of negative experiences, e.g. people being sold unsuitable items (Winchcombe 20o8). Indeed, despite more than 9, ooo studies on the efficacy of eALT being conducted across the world, policy makers have yet to be convinced (McCartney 2012; Stroetmann et al. 2010). However, neither is the current lack of evidence convincing that eALT is completely without effect. The premise that eALT could potentially reduce health and social care costs is a key driver for continued research in this area (Stroetmann et al. 2010).

In summary, demographic changes have created an international challenge of an ageing population with predicted dramatically increasing costs on government funded health and care services (Select Committee on Public Service and Demographic Change 2013; World Health Organization 2011). The consumer market offers a potential solution to this challenge, however; generally, consumer awareness of eALT is low. To address the issues of diminishing statutory health and social care budgets in the UK, growing numbers of people in their fifties and sixties taking greater responsibility for their health and wellbeing, and an underdeveloped consumer eALT market, a study was undertaken to explore the challenges in creating a vibrant and consumer-led assisted living market.

\section{Research aims and objectives}

The overall aim of this study was to explore and develop business approaches and innovations required to make eALT more accessible to consumers aged $5^{\mathrm{O}-70}$ years. This was achieved through the following 


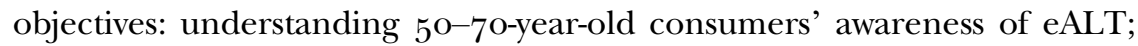
understanding their needs and desires in purchasing eALT; understanding business (manufacturers, suppliers and retailers) perspectives of these consumers and exploring differences between business and consumer perceptions of the market; and using the insights gained to develop and explore new consumer-led business models for the eALT consumer market.

\section{Methodology}

A mixed-method approach was used (Teddlie and Tashakkori 2011), collecting both qualitative and quantitative data from diverse sources to gain a contextual understanding and multi-level perspectives from both individuals aged $5^{\mathrm{O}-70}$ and businesses. To integrate the diverse data collected and to afford a clear interpretation of the research findings from each stage, a conceptual framework was used. A conceptual framework is a research tool intended to assist the researcher to develop awareness and understanding of the situation under scrutiny and to communicate this' (Smyth 2004: 168). A visual display was created to illustrate how the initial consumer data influenced the later stages of the research and business model development and helped to synthesise the data. Findings from each stage were triangulated to validate the data and develop not only an understanding of the market but individual consumers within it. Using a conceptual framework helped to organise ideas emerging from the diverse data sources as well as offering a self-audit facility to ensure cohesion and appropriate conceptualisation for the research conclusions (Lesham and Trafford 2007). The study included the following nine stages.

\section{Market analysis}

Market analysis was carried out to categorise available products, identify the main suppliers and summarise their value propositions, including economy, standard or premium products, routes to market through direct, third party or business-to-business routes, and access to professional advice (Health Design \& Technology Institute 2014).

\section{Product review}

A review of products was undertaken through in-depth interviews with product designers to identify trends in development, types of products currently being developed, and how well they were perceived to meet the needs 
of consumers in their fifties and sixties to identify any gaps in the design of eALT products for this consumer segment.

\section{Consumer street survey}

A survey of 5 oo consumers from five high street locations around the UK sought to understand the importance of different barriers and enablers (identified from a comprehensive literature review) affecting the purchase of eALT. Structured street interviews, lasting approximately 12-15 minutes, were completed. Show cards were used to display a list of answer options and a seven-point Likert scale (with 7 being a very strong influence and 1 being no influence at all) was used to rate the influence of that barrier or enabler on the purchase decision. Participants in the street survey included potential eALT consumers approaching retirement and older age, who may have a long-term health condition or may have caring responsibilities for an older friend/relative. To capture a wide range of consumer views, participants were interviewed from different customer segments; groups $1-4$ were aged $5 \mathrm{O}^{-}-7 \mathrm{O}$ and group 5 comprised slightly younger and older carers: group 1 never bought any eALT $(\mathrm{N}=110)$; group 2 have bought eALT for themselves $(\mathrm{N}=110)$; group 3 have bought eALT for someone else they care for $(\mathrm{N}=110)$; group 4 are users of eALT that was purchased by someone else $(\mathrm{N}=60)$; and group 5 are carers aged $30-44$ or over $71(\mathrm{~N}=110)$.

\section{Consumer focus groups}

Four focus groups were carried out in different UK locations with people aged $5{ }^{\mathrm{O}-70}$ to gain a deeper understanding of their attitudes towards the use and purchase of eALT and the barriers and enablers to eALT adoption for this group of consumers. As with the consumer street survey, participants included current users and non-users of eALT and carers.

\section{Consumer and business co-creation groups}

Six co-creation groups based on Sanders and Stappers (2008) co-creation model were carried out with people aged $50-70$ and eALT business representatives from SMEs (manufacturers, suppliers and retailers) and larger retail and supply companies to develop solutions to overcome the barriers to purchasing eALT identified from the street survey and focus groups. A co-creation methodology was chosen to begin to create a shared vision of a consumer-led eALT market as the ideas and concepts developed during the process had shared ownership between all the participants or 
co-creators. The co-creation method gathered qualitative data in a variety of different media such as notes, artefacts, drawings, mind maps and photographs (Sanders and Stappers 2012). The workshops were conducted in three different locations in England, two groups focused on information needs when purchasing eALT, two on the consumer decision-making process when purchasing eALT and two on the purchase process (Holliday, Ward and Fielden 2015).

\section{In-depth business interviews}

To explore new approaches to business and how business models for the eALT market could be rearranged and developed to align with consumer needs, 12 in-depth interviews were conducted with representatives from medium and large-sized businesses in the assisted living sector whose primary purpose included design, manufacture, distribution and retail, as well as a national charity focused on independent living that also has a sales channel. Interviews were structured around the 'Business Model Canvas' (Osterwalder and Pigneur 2010) which identifies nine elements of a business model that typically influence the operation and potential success of businesses.

\section{Business focus group and telephone survey}

The in-depth business interviews were supplemented with a focus group and telephone questionnaire survey with business representatives $(\mathrm{N}=103)$ meeting the same criteria as those taking part in the in-depth interviews. The focus groups and telephone survey sought to assess their views, understanding and experience of barriers and enablers to the purchase of their products and services for $5^{\mathrm{O}-70}$-year-olds and their perceptions of consumer needs. As with the consumer street survey, the barriers and enablers were presented to participants who were asked to rate their influence on a seven-point Likert scale (with 7 being a very strong influence and 1 being no influence at all).

\section{Business model development}

The business focus group and telephone survey data were triangulated with data from the consumer survey, focus groups and co-creation to define four business models that had resonance within the eALT consumer market. Therefore, the solutions suggested by participants in the consumer studies were then fed into the business modelling process. Business modelling focuses on generating a collaborative effort of value co-creation in which all stakeholders reflect on the value needs of the others with the 
resulting business model acting as the basis for implementation (van Limburg et al. 2011 ).

\section{Business model validation}

Two further focus groups with both consumer and business representatives validated the four business models developed.

\section{Ethical approval}

Where data were collected from people, ethical approval was obtained through Coventry University. Informed consent was obtained from all participants. How their data would be used, the right to withdraw and the assurance of anonymity were explained to participants in detail.

\section{Data analysis}

Consumer street survey and business telephone survey categorical data were analysed using chi-square contingency tables, and ordered data (e.g. sevenpoint Likert scale) using Kruskal-Wallis non-parametric analysis of variance. The in-depth business interviews were recorded, transcribed verbatim and analysed by two research team members, with coding and recoding of the transcripts carried out in order to maintain consistency and improve reliability, and data were analysed using NVivo Version 10 software (QSR International 2012 ). Focus group recordings were transcribed verbatim and data were analysed using thematic content analysis (Green and Thorogood 2004).

Materials generated from the co-creation groups were carefully preserved. Full annotations were made in situ and materials and annotations produced in the workshops were summarised by the facilitators. A collaborative approach was taken to the co-creation analysis where the facilitators read and re-read the data obtained and researcher annotations were added until the data-sets were considered complete. Thematic content analysis was then used to identify key themes.

\section{Results and discussion}

\section{Understanding 50-70-year-old consumer awareness and needs}

The market analysis and consumer street survey highlighted the eALT consumer market as being in its infancy as only 8 per cent of people surveyed had purchased this type of technology. The top three barriers to making a purchase that were ranked as having a moderate to strong influence for 
$5^{\mathrm{O}-7 \mathrm{O}-y e a r-o l d}$ consumers were: cost; knowing what and where to buy; and lack of awareness that a product that might help exists.

All the enabling factors were rated more highly for influence than the barriers. The top three enablers that encouraged consumers to buy eALT were: believing that a product would really make a difference; a feeling that costs are affordable and worth it; and a belief that the product would make life safer at home. Recognising that eALT can be of help to support people as they age is a key stage in the process of obtaining eALT and using it effectively. Generally people wanted to manage by themselves at home and were open to eALT supporting them to do so.

However, a lack of information was found to be a key barrier to purchase; specifically a lack of consumer awareness of eALT, and the need for more accessible and better information of where to go to buy products and services and what to buy was evident.

The market analysis uncovered inconsistencies in pricing and low levels of competition. The review categorised currently available products on the market (mostly traditional ALT; what may be referred to as community equipment as opposed to electronic ALT), identifying the main suppliers and summarising their approach to the market. Parts of the market were clearly dominated by three suppliers. These suppliers sold their products to a wide range of outlets with wide price variations, indicating that, for the consumer, it was worth shopping around.

Poor design and associated stigma influenced what people chose to (or not to) buy. The product review (Woodcock et al. 2013) explored how well products meet the needs of target consumers. It showed that developers are only now beginning to recognise the market for $5^{0-70-y e a r-o l d s, ~ a n d ~}$ that that this market would be best served through better design of mainstream products, rather than specific products targeted at older people. The focus groups highlighted that $55^{\mathrm{O}-70}$-year-olds do not want to be stigmatised or singled out as in need of 'assistive' products or equipment. There is a need for better design to make eALT more attractive, functional, discreet and easy to use. Business focus groups highlighted poor definition and lack of understanding of the needs of $55^{\mathrm{O}-7 \mathrm{O}-y e a r-o l d ~ c o n s u m e r s, ~ a n d ~ a l s o ~ o f ~ t h e ~}$ potential size and structure of the marketplace.

\section{Understanding the differences between business and consumer views}

Barriers. The comparison between consumer and business views on the prepurchase barriers is shown in Figure 1.

Whilst there was a clear influence of these pre-purchase barriers for both consumers and business participants, significant differences were found between the two groups' ratings for the aspects of fear that a product will 


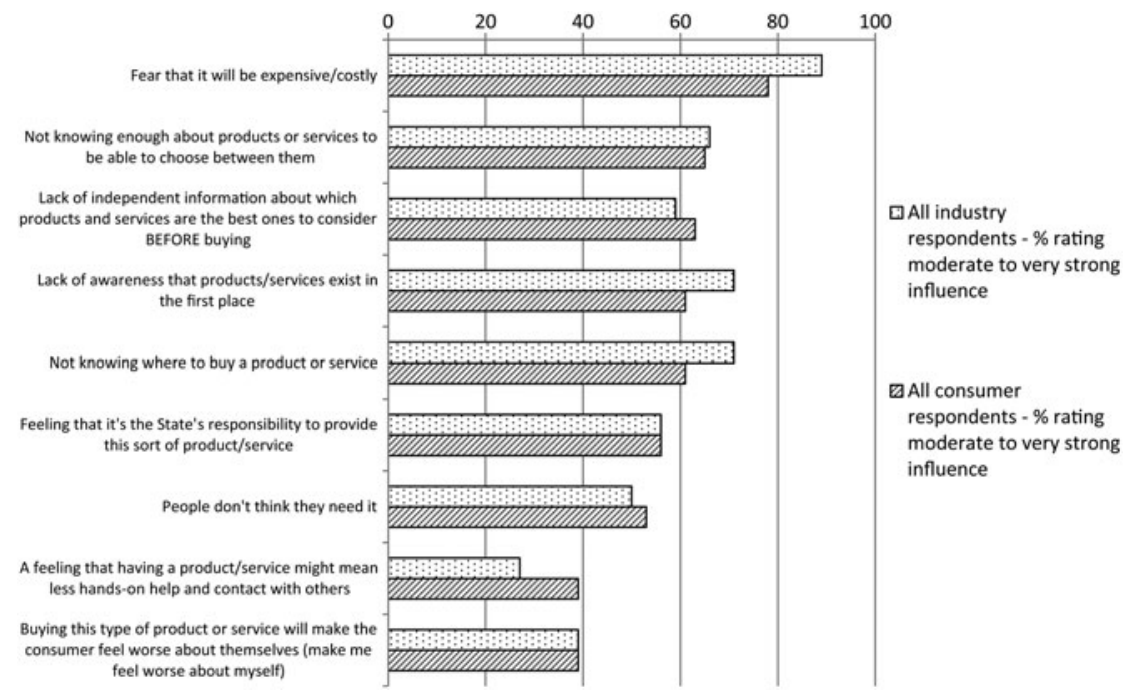

Figure 1. Comparison of consumers' views and industry perceptions of the influence of prepurchase barriers.

Note: Consumers: $\mathrm{N}=5^{\text {oO}}$; industry representatives: $\mathrm{N}=103$.

be costly, lack of awareness that products exist, not knowing where to purchase from and less hands-on help. These differences suggest that business stakeholders perceive these factors to be more significant for $5^{\mathrm{O}-7 \mathrm{O}-\mathrm{year}-}$ olds than they really are, whilst underestimating the 'feeling that using a product or service might mean less hands-on help' has on consumers.

As shown in Figure 2, comparison of which product/service-specific barriers would be influential on purchasing also revealed marked differences between the two groups. One exception to this is affordability: whether consumers can afford to buy in the first place, which is rated as the highest barrier by both groups, and appears to be considerably more influential than the next barrier which is the cost of running the product over a prolonged period.

It appears that business over-estimates the influence of other people's negative attitudes on consumers, but under-estimates the influence of several other factors, including the cost of running a product, its complexity, worries about information disclosure, and lack of national standards, reliability, design and safety.

As shown in Figures 1 and 2, differences were found between consumer and business' views regarding barriers to purchasing and using an eALT product/service. The authors suggest that this lack of understanding of

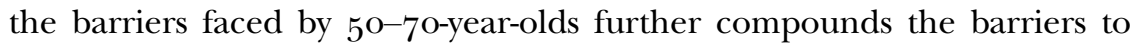
the purchase of eALT. 


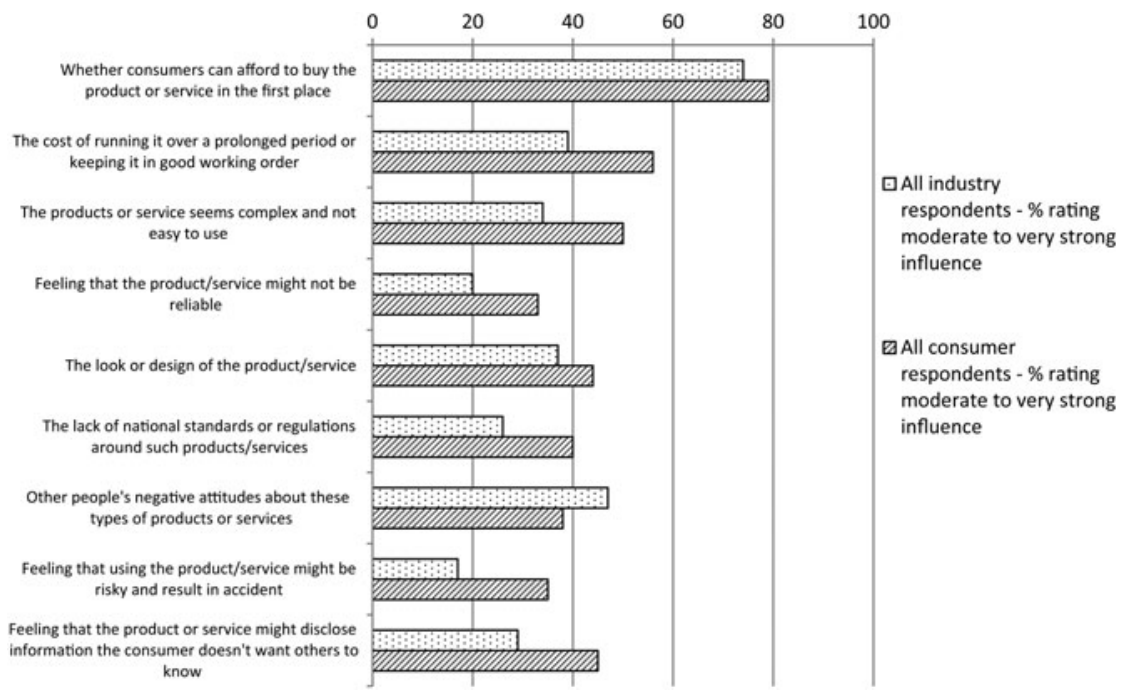

Figure 2. Comparison of consumers' views and industry perceptions of product/service specific barriers.

Note: Consumers: $\mathrm{N}=5^{\mathrm{oo}}$; industry representatives: $\mathrm{N}=103$.

In summary, there are significant differences between what $5^{\mathrm{O}-70-y e a r-}$ old consumers and businesses see as the main barriers to the uptake and use of eALT. This indicates the need for business to pay greater attention to the needs of $5^{\mathrm{O}-70-y e a r-o l d s, ~ w i t h ~ p a r t i c u l a r ~ r e g a r d s ~ t o: ~ e a s e ~ o f ~ u s e, ~ r e l i-~}$ ability, and reassurance to the customer regarding standards and safety. Furthermore, businesses could place greater emphasis on the potential value and benefits of using eALT within their product and service development and marketing strategies.

Enablers. With regard to enablers to eALT purchase, few significant differences were found between the potential consumers in the street survey and business telephone survey, with the exception of the belief that a product would make daily living tasks easier, as Figure 3 shows.

Belief that a product would make daily living tasks easier and knowing that products/services exist to help people are key purchase triggers. Yet these two simple messages - that these products/services can help people overcome a daily living difficulty, and that they simply exist in the first place - are not clearly communicated to consumers by businesses.

\section{Developing solutions and consumer-led business models for the eALT market}

The findings from the focus groups found that information is key to the success of the eALT market; people must recognise a need, they must know 


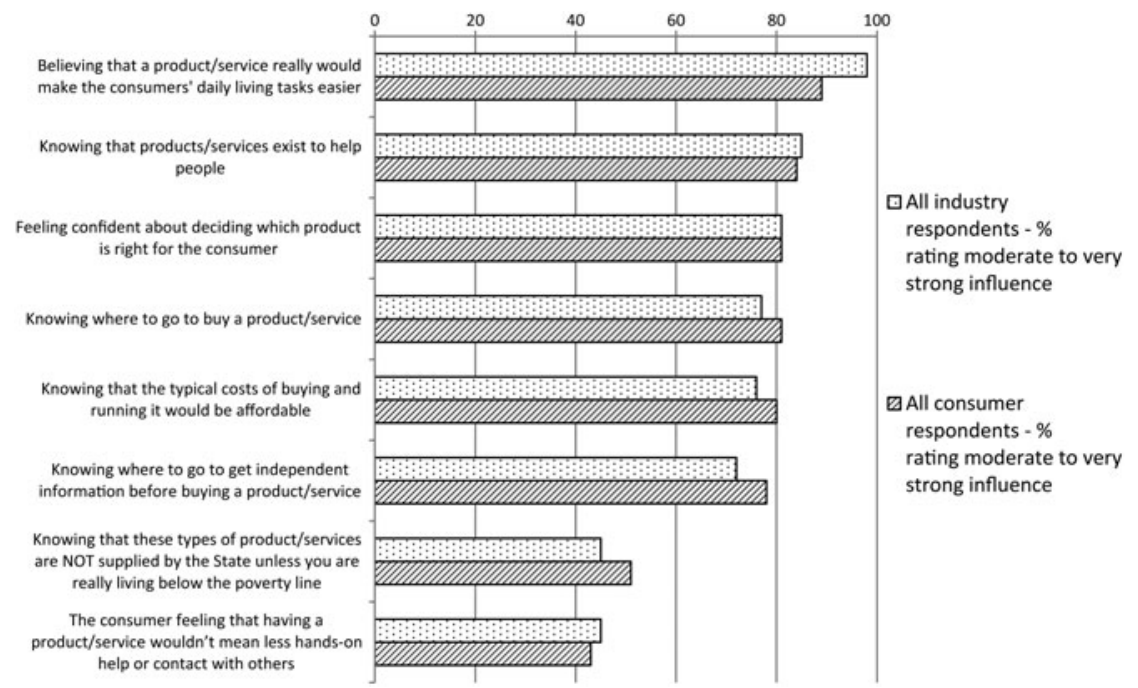

Figure 3. Comparison of consumers' views and industry perceptions of the influence of prepurchase enablers.

Note: Consumers: $\mathrm{N}=5$ oo; industry representatives: $\mathrm{N}=103$.

a product/service exists that might help, they must know where to go to buy it and, finally, they must be supported in making decisions about what to buy.

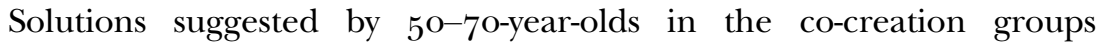
included opportunities for more hands-on experience through demonstrations and 'try before you buy' offers, money-back guarantees, and purchase and rental options. User confidence in the product or service was essential, with reliability and good maintenance and servicing being key factors. They suggested that potential consumers would be helped in the purchase decision-making process by hearing other customers' reviews, along with better information and advice about what to buy. As with any retail purchase experience, outstanding customer service was seen as desirable, but aftersales care and ongoing advice as health and wellbeing needs changed in the future was regarded as essential. Following the business modelling phase of the project, four promising business models for the consumer eALT market emerged. The main features of each model are described in Table 1.

The broker model had the most positive response from both the $5^{\mathrm{O}-7 \mathrm{O}^{-}}$ year-olds and the business experts in the validation focus groups, as it acknowledges the role of expert advice traditionally given by a health or social care expert, who is independent of sales being made; whilst the insurance model was less well supported by the business experts and the consumers. How independent expert advice is provided within a consumer 


\begin{tabular}{|c|c|c|c|}
\hline Business model & Features of the business model & eALT market example & $\begin{array}{l}\text { Customer value } \\
\text { proposition }\end{array}$ \\
\hline Complementor & $\begin{array}{l}\text { A complementor to a product or service is any other } \\
\text { product or service that makes it more attractive. } \\
\text { Two companies co-operate with each other to } \\
\text { create new business opportunities. Automatic free }\end{array}$ & $\begin{array}{l}\text { A company that sells stair lifts partnering with a } \\
\text { company selling falls-monitoring telecare devices } \\
\text { to share a customer base whose primary concern } \\
\text { is that of safety and falls within the home. }\end{array}$ & $\begin{array}{l}\text { A number of my } \\
\text { needs can be met } \\
\text { from one place }\end{array}$ \\
\hline
\end{tabular}

Diversifier A company offers additional products, benefits or services outside their normal area of expertise. This can be developed themselves, outsourced or branded through some form of 'own labelling' agreement. Co-operation could be through a variety of arrangements, e.g. strategic alliance, outsourcing agreement or joint venture.

Independent advisor/broker
A consultant (broker) would identify the customer's needs, then select and bundle a range of products or services into a bespoke solution that meets their independent living needs to support and offer this to the customer.
A monitoring service provided by an energy company which, in addition to their normal energy supply role, provides a remote environmental monitoring service that allows you to check security, appliances and safety of loved ones.

(a) Travel Agent Model where bespoke solutions recommended by broker and chosen bundled into a package. The broker takes commission to pay for expertise provided.

(b) Personal Shopper Model where the customer is signposted to the recommended products and services, which are paid for individually. The broker can be paid by the outlet, or charge the customer a separate amount for their service.
I know I can rely on that brand

\section{I can rely on an} expert 
Insurance

This model is based on a variation of the insurancebased principle, where for insurance against the risk of financial loss or need, many premium payers pay for the few claimants. (a) Life assurance model, where premiums are paid over a period of time in preparation for anticipated expenses related to support for independent living needs.

(b) Cash plan model whereby one pays a set monthly fee, and when expenses such as dental, optical and prescription costs are incurred, you can claim back benefits in the form of cash payments. This could include payment for assisted living products and services.
The worry and uncertainty of the future is managed 
market needs to be considered carefully by businesses to ensure that it has credibility and gains consumer trust.

Drawing on these insights, a business support system was developed to help organisations consider the four different models and how they might be applied in the context of that specific business. The Business Model Canvas (Osterwalder and Pigneur 2010) structure was employed as the foundation for the consumer-led business modelling in this study, and was used to create a Web-based tool to guide businesses through a series of reflective questions aimed at encouraging new thinking and approaches to market development based on what $50-70$-year-olds value in this market. The system was tested and refined with business representatives and is under further development.

\section{Conclusion}

In the UK, the assistive technology market is constructed as a unique statutory and consumer market mix. In order to maintain equality and fairness of access to services, statutory services must continue to ensure that those with low income are provided for in older age. However, as budgets for publicsector services are being reduced, the consumer market must expand to meet growing levels of need and demand that otherwise may overwhelm public services.

This research has improved our understanding of the issues around the potential for the growth of the eALT consumer market. Information and under-

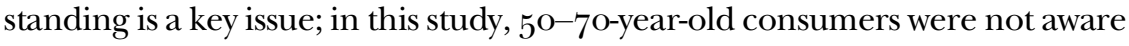
of the existence of eALT products or services and they did not know where to get essential information, indicating that current market approaches are ineffective in reaching this consumer group. Importantly, their self-perception suggests that they do not think they need these products, believing that eALTs are for disabled people or older, frailer people than themselves. Attractive design is an important concern for this group of consumers; yet eALTs are being marketed, in the main, by businesses in a way that promotes disability rather than health, wellbeing and positive lifestyles.

Recognising a need is a significant stage of the consumer purchase process and once a need is recognised, people should know where to go to buy and be supported in making a purchase decision. Strategies to improve information and marketing directed towards this sector of the consumer market must be developed to appeal to potential consumers. Although cost and affordability are issues, this study found that consumers aged $5^{\mathrm{O}-70}$ are willing to buy products if they are thought to be good value and will make a difference to their lives in terms of living independently. However, the research also found a 
significant disconnect between business' perceptions of what $55^{0}-70$-yearolds are looking for in the eALT market, and that existing businesses in this sector are largely set up to serve statutory services rather than discerning consumers. This mismatch in views is perhaps a legacy of the public sector's role in providing eALT to older people and those with disabilities, where the purchaser often has not been the end-user.

There is greater synergy between both groups' views about what factors encourage and those that are a barrier to the purchase of eALT. Enablers were rated as more influential than barriers, suggesting that positive marketing messages about the lifestyle benefits of using eALT products and services would be powerful and could provide greater assurances for $5^{\mathrm{O}-7 \mathrm{O}-\text { year-old }}$ consumers. As discussed by van Limburg et al. (2011), this research confirms that the current eALT market development suffers from a lack of infrastructure, inability to find funding, complications with scalability, and uncertainties regarding effectiveness and sustainability. These issues can be addressed by defining a better implementation strategy through the use of business modelling that is informed by an understanding of the needs and desires of the $5^{\mathrm{O}-} 7 \mathrm{O}-$ year-old consumers. From the four business models explored, the 'Broker' or 'Independent Advisor' business model

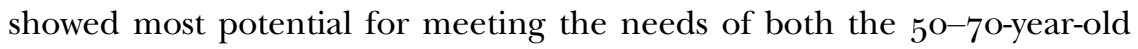
consumers and business stakeholders. A change in direction is needed from public-sector 'provision' to a commercial consumer experience. It is also clear that new partnerships and collaborations are required between businesses and consumers, and that these partnerships should be based

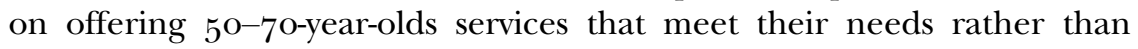
stand-alone products. New business partnerships and service solutions rather than single-product development will be the game changer in the consumer eALT market in terms of scalability and sustainability. Identifying gaps and failings in the market is crucial, and emerging spaces for innovation need to be identified between formal (statutory) care and informal self-support in the eALT consumer market.

\section{Acknowledgements}

The authors would like to thank its project partners Age UK and Grandparents Plus along with Years Ahead and South East Health Technology Alliance for their collaboration and assistance throughout the study. Finally, the authors thank the $46 \mathrm{com}-$ panies who formed the industry advisory group and all the people who took part in the research. This work was funded by the Technology Strategy Board (now Innovate UK) through the Assisted Living Innovation Platform. The authors certify that there is no conflict of interest with any financial organisation regarding the material presented in the paper. 


\section{References}

Age UK 2010. The Golden Economy: The Consumer Marketplace in an Ageing Society. Age UK, London.

Age UK 2011 . Living on a Low Income in Later Life. Age UK, London.

Audit Commission 2004. Older People: Assistive Technology-Independence and Wellbeing. Audit Commission, London.

Audit Scotland 201 2. Commissioning Social Care. Available online at http://www.auditscotland.gov.uk/docs/health/2012/nr_120301_social_care.pdf [Accessed 18 September 2014].

Blashcke, C. M., Freddolino, P. P. and Mullen, E. E. 2009. Ageing and technology: a review of the research literature. British Journal of Social Work, 39, 4, 641-56.

Care Act 2014. Care Act c 232014 . Available online at http://www.legislation.gov.uk/ ukpga/2014/23/pdfs/ukpga_20140023_en.pdf [Accessed 22 July 2014].

Carers UK 2013. Potential for Change: Transforming Public Awareness and Demand for Health and Care Technology. Carers UK, London.

Coughlin, J. 1999. Technology needs of aging boomers. Issues in Science and Technology, 16, 10, 53-6o.

Department of Health 201 2. Long-term Conditions Compendium of Information. Third edition. Available online at https://www.gov.uk/government/publications/longterm-conditions-compendium-of-information-third-edition [Accessed 22 July 2014 ].

Green, J. and Thorogood, N. 2004. Qualitative Methods for Health Research. Sage, London.

Health Design \& Technology Institute 2014. Understanding Consumer Needs in a Changing Assisted Living Market: Insights for Industry. Available online at www. comodal.co.uk [Accessed 27 August 2015].

Higgs, P. F., Hyde, M., Gilleard, C.J., Victor, C. R., Wiggins, R. D. and Jones, I. R. 2009. From passive to active consumers? Later life consumption in the UK from 1968-2005. Sociological Review, 57, 1, 102-24.

Holliday, N., Ward, G. and Fielden, S. 2015. Understanding younger older consumers' needs in a changing healthcare market-supporting and developing the consumer market for electronic assisted living technologies. International Journal of Consumer Studies, 3, 4, 24-31.

Jang, S. and Ham, S. 20og. A double-hurdle analysis of travel expenditure: baby boomer seniors versus older seniors. Tourism Management, 3o, 3, 372-80.

Lesham, S. and Trafford, V. 2007. Overlooking the conceptual framework. Innovations in Education and Teaching International, 44, 1, 93-105.

McCartney, M. 2012. Show us the evidence for telehealth. British Medical Journal, 12, e469, $1-2$.

Office for National Statistics 2009. Wealth in Great Britain: Main Results from the Wealth and Assets Survey 2006/o8. Office for National Statistics, Newport, UK.

Office for National Statistics 201 1. Population Estimates for UK, Mid-2OIo. Office for National Statistics, Newport, UK.

Osterwalder, A. and Pigneur, Y. 2010. Business Model Generation: A Handbook for Visionaries, Game Changers, and Challengers (Portable Version). OSF, Switzerland.

QSR International 2012. NVivo Qualitative Data Analysis Software, Version Io. QSR International, Melbourne.

Reisenwitz, T. and Iyer, R. 2007. A comparison of younger and older baby boomers: investigating the viability of cohort segmentation. Journal of Consumer Marketing, 24, 4, 202-13.

Ross, K. 2008. I 3 Truths About Baby Boomer Travel: Travel Marketing Decisions. Available online at http://www.atme.org/pubs/archives/77_253_1108.cfm [Accessed 21 June 2011]. 
Sanders, E. and Stappers, P. 2008. Co-creation and the new landscapes of design. International Journal of CoCreation in Design and the Arts, 4, 1, 5-18.

Sanders, E. and Stappers, P. 2012. Convivial Toolbox: Generative Research for the Front End of Design. BIS, Amsterdam.

Select Committee on Public Service and Demographic Change 2013. Ready for Ageing? Stationary Office, London.

Smyth, R. 2004. Exploring the usefulness of a conceptual framework as a research tool: a researcher's reflections. Issues in Educational Research, 14, 1, 167-80.

Social Care Institute for Excellence 2013. Fair Access to Care Services (FACS): Prioritising Eligibility for Care and Support. Available online at http://www.scie.org.uk/publica tions/guides/guide33/files/guide33.pdf [Accessed 22 July 2014].

Stroetmann, K. A., Kubitschke, L., Robinson, S., Stroetmann, V., Cullen, K. and McDaid, D. 2010. How Can Telehealth Help in the Provision of Integrated Care? World Health Organization Regional Office for Europe, Geneva.

Teddlie, C. and Tashakkori, A. 2011 . Mixed methods research. In Denzin, N. K. and Lincoln, Y. S. (eds), The Sage Handbook of Qualitative Research. Fourth edition, Sage, London, $285^{-99}$.

van Limburg, M., van Gemert-Pijnen, J. E., Nijland, N., Ossebaard, H. C., Hendrix, R. M. and Seydel, E. R. 2011 . Why business modelling is crucial in the development of eHealth technologies. Journal of Medical Internet Research, 13, 4, e 124.

Walker, A. 2009. Commentary: the emergence and application of Active Ageing in Europe. Journal of Ageing and Social Policy, 2 1, 1, 75-93.

Ward, G. and Ray, S. 2014. Unlocking the Potential of the Younger Older Consumer. Available online at www.comodal.co.uk [Accessed 23 July 2014].

Westbrook, G. 2015. Challenges and Opportunities in Targeting the Senior Consumer. London, Euromonitor International.

Winchcombe, M. 2008. Making disability equipment ordinary: choice, control and the retail model. International Journal of Therapy $\mathcal{E}$ Rehabilitation, 15, 3, $115-8$.

Woodcock, A., Ward, G., Ray, S., Holliday, N., Prothero, L., Osmond, J. and Fielden, S. 2013. Younger older consumers of assistive technology products. In Anderson M (ed), Contemporary Ergonomics and Human Factors. London, Taylor \& Francis, 370-378.

World Health Organization 2011. Global Health and Aging. Available online at https://d2cauhfh6h4xop.cloudfront.net/s3fs-public/global_health_and_aging. pdf [Accessed 7 October 2015].

Yoon, C., Cole, C. A. and Lee, M. P. 20og. Consumer decision making and aging: current knowledge and future directions. Journal of Consumer Psychology, 19, 1, 2-16.

Accepted 5 January 2016; first published online 22 February 2016

Address for correspondence:

Gillian Ward,

Innovation, Design and Technology Unit,

Centre for Technology Enabled Health Research,

Coventry University,

Coventry CV1 5 FB, UK

E-mail: g.ward@coventry.ac.uk 